\title{
PESCA E AQUICULTURA: TÉCNICAS DE EDUCAÇÃO AMBIENTAL NO ENSINO FUNDAMENTAL, NO MARAJÓ (PA)
}

\author{
Ramila Diniz Miranda ${ }^{1}$, Antonia Rafaela Gonçalves Macedo ${ }^{2}$, Ana Célia \\ Barbosa Guedes ${ }^{3}$, Netanias Mateus de Souza Castro ${ }^{3}$, Julia Siqueira Moreau ${ }^{3}$, \\ Arllen Élida Aguiar Paumgartten ${ }^{3}$, Raoani Cruz Mendonça ${ }^{3}$, Manoel Luciano \\ Aviz de Quadros ${ }^{3}$, Luã Caldas de Oliveira ${ }^{3}$, Fabricio Nilo Lima da Silva ${ }^{* 3}$
}

Resumo: Este trabalho teve como objetivo aplicar técnicas de Educação Ambiental (EA) aos estudantes da escola Adventista de Breves, Arquipélago do Marajó, Pará, Brasil, integrada aos assuntos da pesca e aquicultura. Foi utilizada a abordagem qualitativa e quantitativa. Para coleta de dados foi aplicado um questionário, palestras, atividade virtual de ensino/aprendizagem, demonstrativa e aplicação da escala hedônica facial, para 29 discentes do ensino fundamental. Os resultados indicam que o uso das técnicas de EA são importantes na escola, assim como o direcionamento para gerar mudanças de comportamento em relação ao meio ambiente. Foi possível identificar que $91 \%$ estudantes possuem conhecimentos sobre EA, uma parcela considerável não sabe que a pesca predatória pode acarretar a extinção de peixes, demonstrando que projetos de Educação Ambiental voltados para aquicultura são necessários para uma melhor conscientização ambiental.

Palavras-chave: Recursos Pesqueiros; Meio Ambiente; Percepção; Ensino.

Abstract: This work aimed to apply Environmental Education (EA) techniques to students of the Breves Adventist School, Marajó Archipelago (Pará, Brazil), integrated with fisheries and aquaculture issues. The qualitative and quantitative approach was used. For data collection was applied a questionnaire, lectures, virtual activity of teaching / learning, demonstration and application of facial hedonic scale, for 29 students of elementary school. The results indicate that the use of $A E$ techniques are important in school, as well as the direction to generate behavioral changes in relation to the environment. It was possible to identify that $91 \%$ students have knowledge about EA, a considerable portion do not know that predatory fishing can lead to fish extinction, demonstrating that Environmental Education projects focused on aquaculture are necessary for a better environmental awareness.

Keywords: Fishing Resources; Environment; Perception; Education.

\footnotetext{
${ }^{1}$ Estudante do curso Técnico em Meio Ambiente do Instituto Federal de Educação, Ciência e Tecnologia do Pará (IFPA) Campus Breves, Pará, Brasil.

2Doutora em Ciência Animal pela Universidade Federal do Pará (UFPA) Campus Castanhal, Pará, Brasil.

*3 Professor(a) do Instituto Federal de Educação, Ciência e Tecnologia do Pará (IFPA), Campus Breves. Rua Antônio Fulgêncio da Silva, s/n - Bairro: Parque Universitário - CEP: 68.800-000, Breves, Pará, Brasil. E-mail para correspondência: fabricio.nilo@ifpa.edu.br
}

Revbea, São Paulo, V. 15, № 3: 410-425, 2020. 


\section{Introdução}

As discussões acerca da Educação Ambiental (EA) e da defesa do meio ambiente, no Brasil, emergiram na década de 1980, quando os impactos socioambientais passaram a ter mais repercussão na América do Norte e Europa Ocidental. Tais impactos foram causados pela relação homem $x$ natureza, além das relações humanas que se estabeleceram em uma sociedade marcada pelo processo de exploração capitalista. Foi nesse contexto que as discussões ambientais e a conservação dos recursos naturais começaram a ganhar destaque e despertou a "consciência ecológica" e a busca pelo desenvolvimento sustentável (LÍSBOA; BARROS, 2008).

De acordo Constituição Federal de 1988 , no artigo $225^{\circ}$, parágrafo I inciso $\mathrm{VI}$, é dever e obrigação do poder púbico promover a $\mathrm{EA}$ em todos os níveis de ensino e a conscientização pública para a prevenção do meio ambiente (BRASIL, 1998). Assim, as experiências com EA ganharam destaque, sendo criada a Lei 9.795/99, que trata da Política Nacional de EA, procurando assegurar em todas as escolas as práticas dessa educação (BRASIL, 1999). Nesse contexto, surgem os Parâmetros Curriculares Nacionais (PCN), os quais são referência para o ensino fundamental (FERREIRA et al., 2019; VIANA et al., 2019). Esse documento destaca diferentes áreas do conhecimento e temas transversais, como o meio ambiente (BRASIL, 1997). Ele enfatiza que a natureza se trata de uma grande rede de relações entre fenômenos e que o ser humano se torna uma parte integrante desse processo (BERGAMO; GARBIM, 2017). Portanto, a EA é de suma importância, pois trabalha com os recursos naturais de maneira interdisciplinar (BRASIL, 1997; GONÇALVES et al., 2019), sendo comuns aos educandos.

A pesca se baseia na extração de recursos pesqueiros do ambiente natural (FRIEDLANDER, 2018; NEVES et al., 2019). Uma das atividades importante no Brasil, do ponto de vista econômico e social (DAIRIKI; SILVA, 2011; LLORET et al., 2016; DORIA et al., 2018, BROWNSCOMBE et al., 2019). $\mathrm{Na}$ aquicultura existe a piscicultura (BALDISSEROTTO et al., 2018), a carcinicultura (MACIEL; VALENTI, 2014), a quelonicultura (MAGNUSSON et al., 2003), a malacocultura (SAMPAIO et al., 2017), entre outros organismos aquáticos e semiaquáticos.

No ambiente escolar, essas atividades podem ser trabalhadas, pensadas e discutidas de forma integrada (VAROTTO; ARAÚJO, 2016). Desse modo, a partir da EA o estudante poderá conhecer e diferenciar características da pesca e aquicultura (SILVA JÚNIOR et al., 2019). Reflete sobre os aspectos do desenvolvimento sustentável dessas atividades em processo de formação escolar (SILVA et al., 2019). Com a disciplina de biologia, por exemplo, podese trabalhar as características das espécies de peixes; na física, as características dos ecossistemas aquáticos; e, na química, a qualidade da água. Vale ressaltar, que a aquicultura nasce como uma alternativa à pesca predatória, sendo importante abordar os efeitos que ela causa, de maneira que 
esclareça a importância da preservação do meio ambiente (APPOLO; NISHIJIMA, 2011).

Na Amazônia, em especial no Arquipélago do Marajó (Pará - Brasil), a pesca é de suma importância para agricultores, pescadores e ribeirinhos, para o sustento e comercialização. No entanto, a piscicultura vem ganhando destaque por ser uma atividade rentável. No município de Breves, por exemplo, é de extrema importância no contexto socioeconômico, principalmente com a criação do tambaqui (Colossoma macropomum Cuvier, 1818), entre outros peixes (SILVA et al., 2017). Embora seja uma espécie apreciada pelas comunidades ribeirinhas e urbanas, os estoques naturais vêm sofrendo redução, pela pesca predatória na região. Assim, utilizar técnicas de EA na perspectiva de incentivar à piscicultura nas escolas torna-se uma alternativa à exploração dos recursos pesqueiros (MENEZES et al., 2011).

A Escola de Ensino Fundamental Adventista de Breves recebe, como educandos, filhos e filhas de famílias da zona urbana e rural que conhecem a pesca ou praticam a piscicultura do tambaqui em suas comunidades. A região do Marajó é rica em biodiversidade (rios e floresta), com constantes atividades de exploração, para subsistência e comercialização. Inserir a piscicultura no contexto escolar como instrumento de EA se concretiza como uma estratégia viável (MAGALHÃES, 2010), para a continuidade da atividade aquícola. Além de ser um instrumento de reflexão sobre as necessidades de conservação dos recursos pesqueiros, o espaço escolar tem o papel decisivo para que a EA se efetive através das influências geradas a partir das práticas e técnicas vivenciadas (MELO; TRAJBER, 2007).

Assim, o objetivo foi aplicar técnicas de Educação Ambiental (EA) aos estudantes do município de Breves (Pará, Brasil), para promover discussões sobre aquicultura como alternativa à pesca predatória, bem como a conservação da ictiofauna no Arquipélago do Marajó.

\section{Material e Métodos}

\section{Área de estudo}

A pesquisa foi realizada na Escola Adventista de Breves, no Arquipélago do Marajó, Pará, Brasil, durante os meses de junho a agosto de 2019 (Figura 1). A escola faz parte da associação Baixo Amazonas da Igreja Adventista do Sétimo Dia (ABA-IASD). Atualmente, conveniada à Prefeitura Municipal de Breves, em especial à Secretaria Municipal de Educação (SEMED). Em 2017, possuía um total de 357 estudantes regulamente matriculados contendo sete turmas, distribuídos em dois turnos (matutino e vespertino), com destaque para a modalidade do ensino fundamental (anos iniciais de $1^{\underline{a}}$ ao $5^{\circ}$ ano). De acordo com o Projeto Político Pedagógico (PPP) da escola, um de seus objetivos é oportunizar a construção do conhecimento como meio para o exercício da cidadania, norteado por valores cristãos. Com relação às ações de caráter pedagógico, a escola dispõe projetos de reforço escolar para alunos com 
dificuldades de aprendizagem. Considera que tais dificuldades são obstáculos para a permanência dos educandos e a consequente continuidade dos estudos.

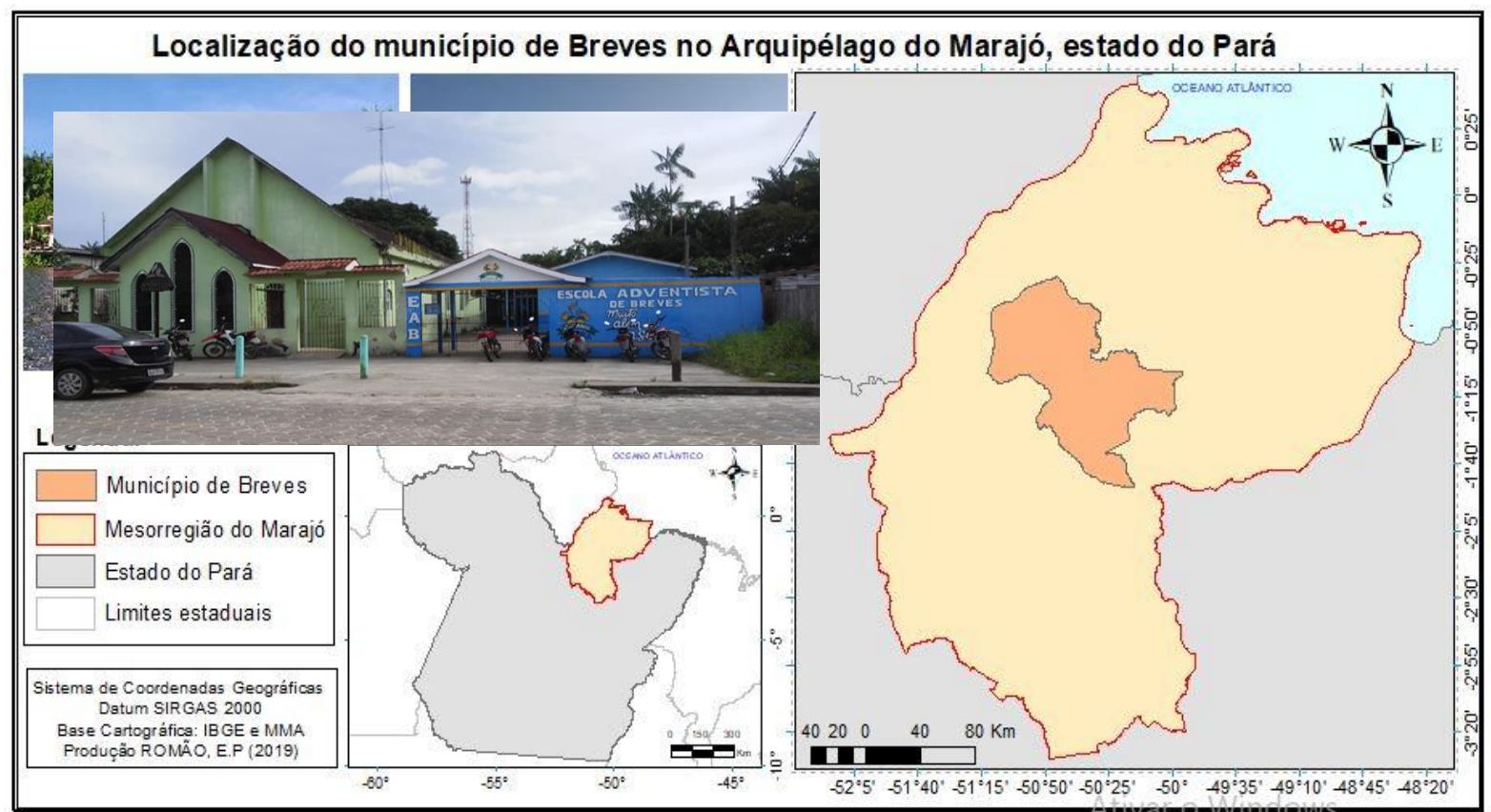

Figura 1: Mapa do município de Breves, Marajó, Pará, Brasil. Fonte: Essia Romão (2019).

O Arquipélago do Marajó é formado por cerca de 2.500 ilhas, com 16 municípios. Ao sudoeste do arquipélago, à margem esquerda do rio Pararauaú está o município de Breves. Essa cidade apresenta uma extensão territorial de $9.563,007 \mathrm{~km}^{2}$ e uma população estimada de 101.891 habitantes (IBGE, 2010). A hidrografia da região é formada pelos rios Amazonas, Pará, Anapu, Jacundá e Anajás, com seus numerosos afluentes que compõem redes de drenagem de canais recentes, como: riachos, bacias, canais, meandros e lagos. O local apresenta uma vasta biodiversidade (fauna e flora), sendo os rios a principal via de locomoção. Nessa região, a fonte de renda é proveniente do serviço público, do agroextrativismo e do comércio, com destaque para agricultura, pesca e aquicultura familiar, com a criação do tambaqui.

\section{Coleta de dados}

A coleta de dados foi de caráter quali-quantitativo. O estudo foi conduzido com 23 educandos do $5^{\circ}$ ano da escola Adventista de Breves, do turno da manhã. Foram aplicadas técnicas de EA, em cinco etapas metodológicas: Etapa 1 - aplicação de questionários, Etapa 2 - palestras, Etapa 3 - atividade virtual de ensino/aprendizagem, Etapa 4 atividade demonstrativa e Etapa 5) - questionário pós-atividades: escala hedônica facial. 
Primeiro, foi elaborado um questionário semiestruturado, com perguntas abertas e fechadas, sobre a pesca e a aquicultura, aplicados aos estudantes. $\mathrm{O}$ uso do questionário é uma técnica que aborda questões aos indivíduos com a intenção de alcançar informações sobre crenças, valores e comportamentos (GIL, 2012). A intervenção foi executada por meio de palestra. Inicialmente, foi conceituado o tema "meio ambiente" levando em consideração o ambiente natural e artificial. Foram abordadas questões sobre o meio ambiente e os principais problemas existentes no Marajó como queimadas, desmatamento, extinção de animais, poluição do solo e da água. Foi possível discutir os problemas ambientais presentes no dia a dia das pessoas nas comunidades locais e destacar os impactos causados pela pesca predatória. Alguns conceitos foram essenciais durante a utilização das técnicas de EA, dentre eles: sustentabilidade, preservação, conservação, assim como atividades da piscicultura do tambaqui em Breves e região marajoara, sendo utilizadas como estratégia de educação e preservação ambiental.

Foi apresentado aos estudantes dois vídeos: 1) "Vamos Cuidar do Meio Ambiente" (Clips da turma, 2011), que expressa os impactos no meio ambiente causado pelos humanos e 2) "Água" (Desenho Ambiental, 2011), é uma curta animação, cujo personagem é um peixe, que percorre uma trajetória sobre sua vida aquática a partir dos impactos gerados pelo uso da água sem devidos cuidados. Assim, descreve a influência que estas atitudes podem exercer nos ecossistemas aquáticos. Esses vídeos foram usados a partir da ludicidade como técnica de EA, sendo essencial para despertar nos estudantes a associação do que foi trabalhado. Utilizar recursos virtuais se caracteriza como um auxílio pedagógico atraente, principalmente para o discente. Tal recurso se apresenta como uma possibilidade didática em relação ao objetivo de ensino, favorecendo a apropriação de saberes, por meio das imagens e sons apresentados (BOMZANINI; NUNES, 2015).

Foi realizada uma demonstração de peixes em aquários, com o "peixe betta" (Betta splendens) (BOTELHO FILHO; OLIVEIRA, 1984; MENEZES et al., 2011). O aquário inserido em sala de aula é uma importante ferramenta didática no que se refere ao processo de ensino e aprendizagem de conteúdos, sendo esta uma área que carece de recursos didáticos que relacionem a teoria com os fenômenos naturais observáveis (OLIVEIRA et al., 2013). Por ser uma técnica que auxilia aos alunos a compreender de maneira prática como funciona a criação de peixe em ambiente confinado, explorando o significado desta atividade para meio ambiente a partir do trabalho com a piscicultura na região do Marajó. Foi possível explicar e demostrar como é esse tipo de prática, esclarecendo as dúvidas e as associando a uma estratégia de preservação ambiental, quando se adota as boas práticas de manejo. Atividades demonstrativas possibilitam uma observação em grupo, que posteriormente, gera uma discussão sobre o assunto (KRASILCHIK, 1998). A partir dessa perspectiva, foi possível assegurar a participação dos estudantes, além de despertar curiosidades e interesse sob tal atividade, assim como trabalhar o cuidado com natureza e seus recursos naturais. Foi utilizado uma 
escala hedônica facial, com cinco categorias diferentes adaptadas de Dutcosky (2007). As respostas imediatas, quando se trata do público alvo da esfera infantil, apresenta-se como fonte de informação e coleta dados (AFONSO, 2017; GIL, 2012).

Todos os educandos foram conscientizados sobre a contribuição voluntária, os benefícios e objetivos da pesquisa em questão. Por se tratar do público do ensino fundamental, logo, todos menores de idade, foi utilizado o termo de consentimento livre e esclarecido (TCLE), destinado aos pais ou responsáveis dos alunos, para autorização de participação no projeto. Os responsáveis legais foram informados sobre o uso das informações fornecidas em trabalhos científicos e foi garantido o anonimato. Os dados foram analisados usando estatística descritiva.

\section{Resultados e Discussão}

Um total de $61 \%$ dos estudantes que participaram deste estudo era do sexo feminino e $39 \%$ do masculino, com faixa etária entre 9 a 12 anos (Figura 2). A idade deles estão dentro das conformidades para o ensino fundamental (entre 10 anos incompletos a 12 anos de idade) (BRASIL, 2010). Pesquisas apontam que essa faixa de idades é excelente para trabalhar com a EA (ALARCON et al., 2019; VERDELONE et al., 2019). Para Medeiros et al. (2011), as crianças estão em fase de desenvolvimento, a qual é a melhor idade para aprender, destacando ainda que quando "inocentes" se torna mais fácil moldar-se novos conhecimentos, pelo contrário, os adultos já possuem hábitos e comportamentos concretizados e de difícil reorientação.

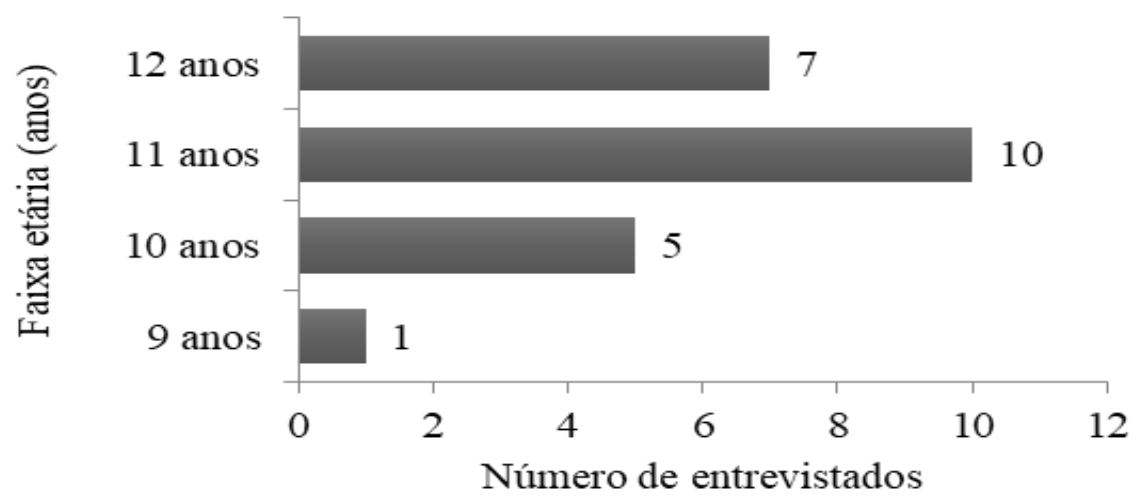

Figura 2: Faixa etária dos estudantes (técnica de entrevista), Breves, Ilha do Marajó, Pará, Brasil.

Em nosso estudo, 91\% dos estudantes afirmaram saber o que é EA (Figura 3). Uma vez que já ouviram falar do assunto em livros, revistas e mídias, contudo não sabem compreender apenas o significado de forma científica. Foi observado que a maioria deles já teve contado com o tema, 
sendo de extrema relevância discutir pesca e aquicultura no espaço escolar. 0 interesse pela preservação do meio ambiente e o desenvolvimento da aquicultura deve ser incentivado junto aos alunos, pois com a conscientização das novas gerações, através da educação, é possível ter um ambiente sustentável que possibilite a reprodução das espécies animais e vegetais (SOUZA; MURATA, 2011). Para que o estudante compreenda a importância da EA, é necessário que o docente desenvolva metodologias adequadas para trabalhar este conceito em sala de aula. Nas escolas há uma maior preocupação em relação a abordagem da EA, e o tema vem sendo progressivamente inserido em cursos de graduação e pós-graduação (VIANA et al., 2019).

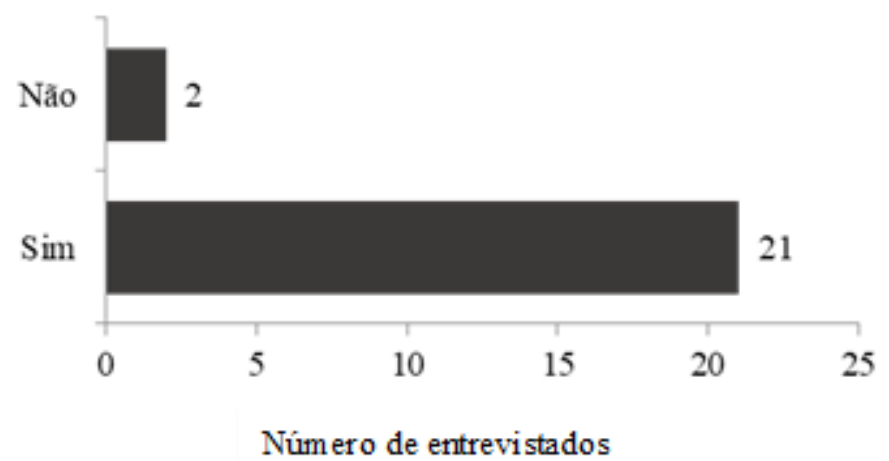

Figura 3: Conhecimento sobre EA pelos estudantes (técnica de entrevista), Breves, Ilha do Marajó, Pará, Brasil.

Os estudantes que participaram do presente estudo, são indivíduos que estão cursando o ensino fundamental. Logo, essa etapa perpassa por uma série de mudanças não somente nos aspectos físicos, mas também por possíveis alterações cognitivas, emocionais e sociais. Trabalhar com EA no ensino fundamental de forma transversal é um dos objetivos dos Parâmetros Curriculares Nacionais (BRASIL, 1997). Portanto, temas como pesca e aquicultura podem ser discutidos em assuntos de EA na escola. Esta deve ser abordada dentro de todas as disciplinas com o intuito de construir valores para que os cidadãos possam transformar a realidade que conhecem em algo melhor (TERTULIANO; FIORI, 2019). Para que isso aconteça, os PCN orientam que a realidade do aluno e os problemas locais sejam valorizados durante os estudos.

Os estudantes que entendem sobre meio ambiente? Muitos foram enfáticos em dizer: "...eu entendo que o meio ambiente precisa ser preservado, ele precisa do nosso cuidado, porque ajuda ele e nos mesmos..." (Estudante A, 10 anos). Percebamos que o meio ambiente é essencial para a vida humana, isto é, o cuidado com o meio ambiente reflete diretamente na qualidade de vida dos seres humanos em resultados significativos para ambas as partes. Os estudantes possuem uma visão antropocêntrica, onde respostas como essa dar indício que os recursos naturais são unidades básicas para a sobrevivência humana (REIGADA, TOZONI-REIS, 2004). Os demais educandos do ensino 
fundamental tiveram resposta semelhantes e, ao que parece, foram motivados pelo senso comum em suas respetivas respostas. Assim, percebemos que 0 ensino da Educação Ambiental ainda se assemelha ao pensamento de Reigota (2007), como preservacionista, o qual dá ênfase à maneira como o homem influencia no meio, mas tão pouco utiliza fatos reais do conviveu social, cultual ou até mesmo econômico, para desencadear nos discentes sabres socioambientais que podem ser gerados a partir de uma atividade própria da sua região ou convívio familiar

Neste estudo, os estudantes destacaram entendimentos sobre poluição ambiental e degradação dos rios no Marajó, um estudante afirma que: "...a poluição ambiental é quando tem lixo nos rios, poluição por carro da fumaça deles e poluição visual..." (Estudante B, 9 anos), "...quando as pessoas jogam lixo no rio, como garrafas, sacola, metade da comida para os peixes..." (Estudante $\mathrm{C}, 12$ anos). Percebe-se que os alunos já conseguem distinguir 0 que seria poluição a partir da visualização do meio ambiente. Fica entendido ainda que são passivos da incompreensão de como esses atos podem influenciar biologicamente, quimicamente e fisicamente para a extinção dos recursos naturais. Para alcançar tal entendimento nos estudantes, é primordial que as escolas se apoderem de técnicas de EA que não somente trabalhe conceitos propriamente ditos, mas que utilize das técnicas oferecidas para excitar os aprendizes a dialogar com as atividades cotidianas da sua realidade (TOZONI-REIS, 2008).

No presente estudo, os estudantes sabem identificar os possíveis problemas ambientais nas comunidades do Marajó (Quadro 1). A poluição da água foi o problema mais citado pelos estudantes (31\%). Isso pode estar vinculado ao um fator cultural, sendo que é comum o descarte de resíduos em rios da região, provavelmente pela falta de EA. Entretanto, muitos não perceberam que essa prática pode causar danos nos ecossistemas aquáticos, influenciando na qualidade da água. Prejuízos ambientais nada mais é que uma modificação sofrida no ambiente, causada por ações antrópicas, resultando em fatores negativos para o bem-estar humano e ambiental (KLOETZEL, 2017). Danos causados em corpos hídricos, seja nos aspectos físicos, biológicos ou químicos, torna-se uma constante preocupação (VAROTTO; ARAÚJO, 2016). Dentre os prejuízos que a poluição traz aos seres vivos, destaca-se os seus efeitos negativos sobre a comunidade de peixes. Em vista disso, ainda não existe uma consciência plena dos efeitos do descuido com a natureza, apesar de os programas de EA desenvolvidos nas escolas serem importantes, embora ainda tímidos, instrumentos para prevenir desastres maiores no futuro. 
Quadro 1: Principais problemas ambientais citados pelos estudantes (técnica de entrevista), Breves, Ilha do Marajó, Pará, Brasil.

\begin{tabular}{|c|c|}
\hline Problemas & Frequência (\%) \\
\hline Poluição da água & $31,0 \%$ \\
\hline Lixo & $29,0 \%$ \\
\hline Queimadas & $21,0 \%$ \\
\hline Desmatamento & $11,0 \%$ \\
\hline Redução de animais & $4,0 \%$ \\
\hline Nenhum & $4,0 \%$ \\
\hline
\end{tabular}

A poluição dos rios pode impactar diretamente as atividades econômicas desenvolvidas na região, como por exemplo à pesca. Os estudantes mencionaram uma diversidade de peixes, algumas espécies fazem parte do mercado de peixes ornamentais (Figura 4)

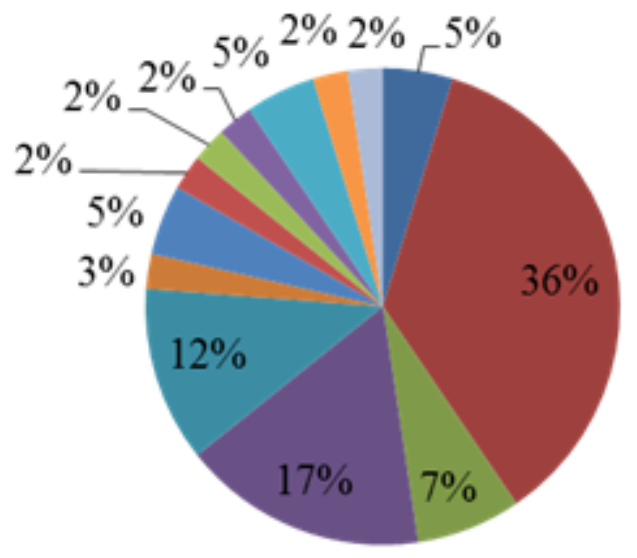

\author{
- Peixe palhaço \\ - Pescada \\ = Pacu \\ - Pirarucu \\ - Tambaqui \\ = Dama azul \\ - Véu de noiva \\ " Não gosto \\ $=$ Piranha
}

Figura 4: Visão dos estudantes da escola Adventista com relação a extinção de peixes (técnica de entrevista), Breves, Ilha do Marajó, Pará, Brasil. 
Vocês sabiam que os peixes podem entrar em extinção?

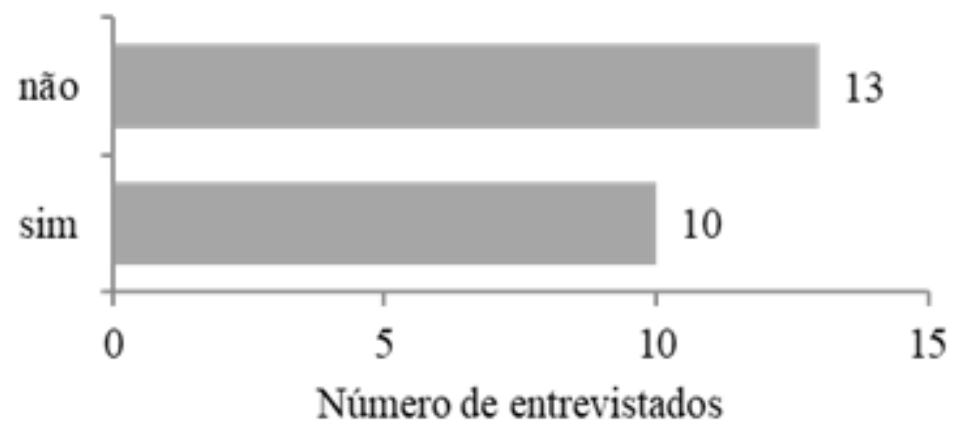

Figura 5: Visão dos estudantes da Escola Adventista com relação a extinção de peixes (técnica de entrevista), município de Breves, Marajó, Pará, Brasil.

Quando se fala de questões ambientais, foi possível discutir pesca e aquicultura por meio de palestras e atividade virtual de ensino/aprendizagem no presente estudo. No que diz respeito à opinião dos estudantes em relação à criação de peixes em viveiros escavados, quando perguntado se seria bom para o meio ambiente. A maioria deles $(57 \%)$ expressaram que adorariam e $35 \%$ disseram que gostariam (Figura 6), além de afirmarem que a pesca predatória é excessiva e insustentável praticada no Marajó.

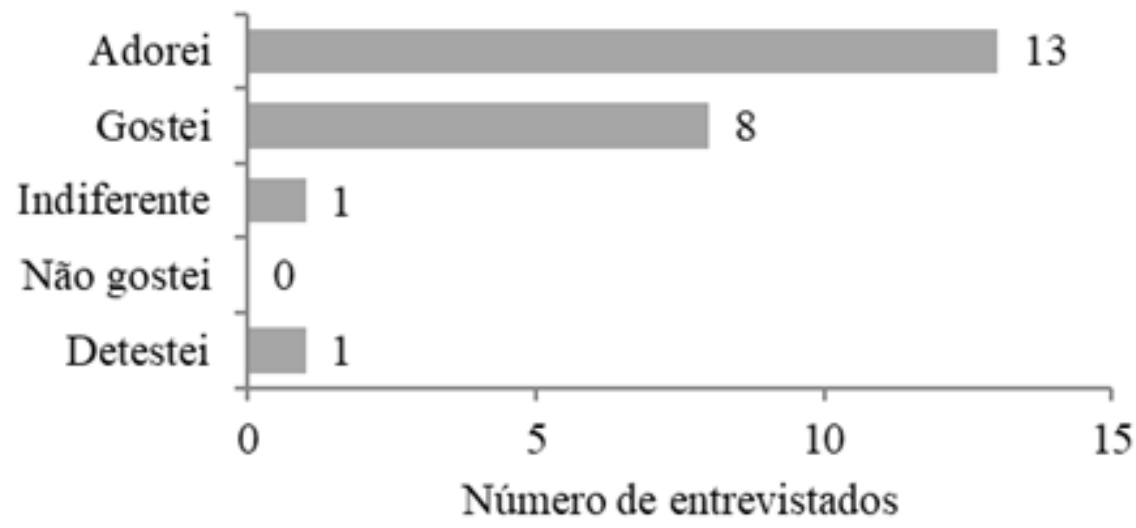

Figura 6: Opinião sobre a criação de peixes em viveiros escavados dos estudantes (técnica escala hedônica facial), Breves, llha do Marajó, Pará, Brasil.

Para Garutti (2003) a aquicultura é entendida como uma atividade agrícola, sendo uma alternativa a pesca predatória. Portanto, essa atividade de discussão se faz necessária no âmbito escolar, em especial nas disciplinas do eixo das ciências naturais (física, química e biologia) (SOUZA; MURATA, 2011), pois está inserida dentre as atividades exercidas no Marajó. Essa região 
apresenta numerosos afluentes, que propiciam a prática de diversas modalidades de pesca e a piscicultura.

No presente estudo, os estudantes conseguiram visualizar e entender 0 que seria a piscicultura na prática (Figuras 7 e 8). Além disso, foi possível discutir por meio dessa atividade demonstrativa as técnicas de EA. Conseguimos despertar no estudante a responsabilidade sobre as boas práticas de manejo na piscicultura, como o hábito alimentar dos peixes, etapas de criação, qualidade da água, ração e frequência alimentar, entre outros. Essa combinação entre o tema (pesca e aquicultura) e a técnica de EA (atividade demonstrativa), contribui para os estudantes mais entusiasmado com as aulas, desencadeamento atitudes no que tange ao meio ambiente, auxiliando para desenvolver o ensino aprendizagem do conteúdo explanado (OLIVEIRA et al., 2013).
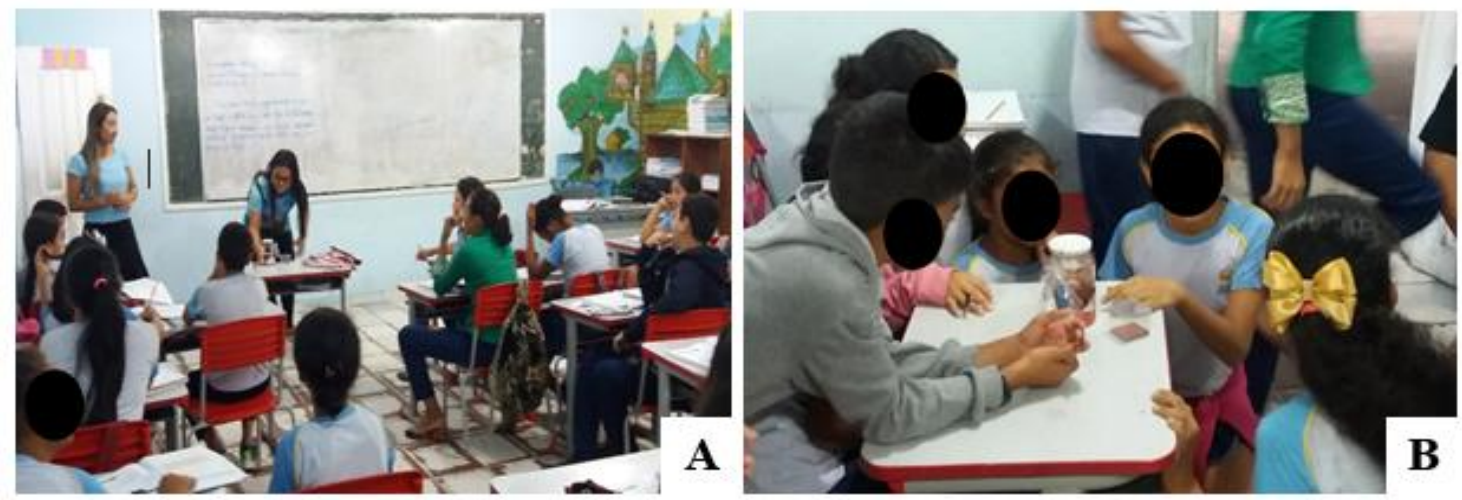

Figura 7: (A) momentos da entrega de aquários para os alunos e (B) momentos da atividade expositiva com os estudantes (técnica demonstrativa), Breves, llha do Marajó, Pará, Brasil.
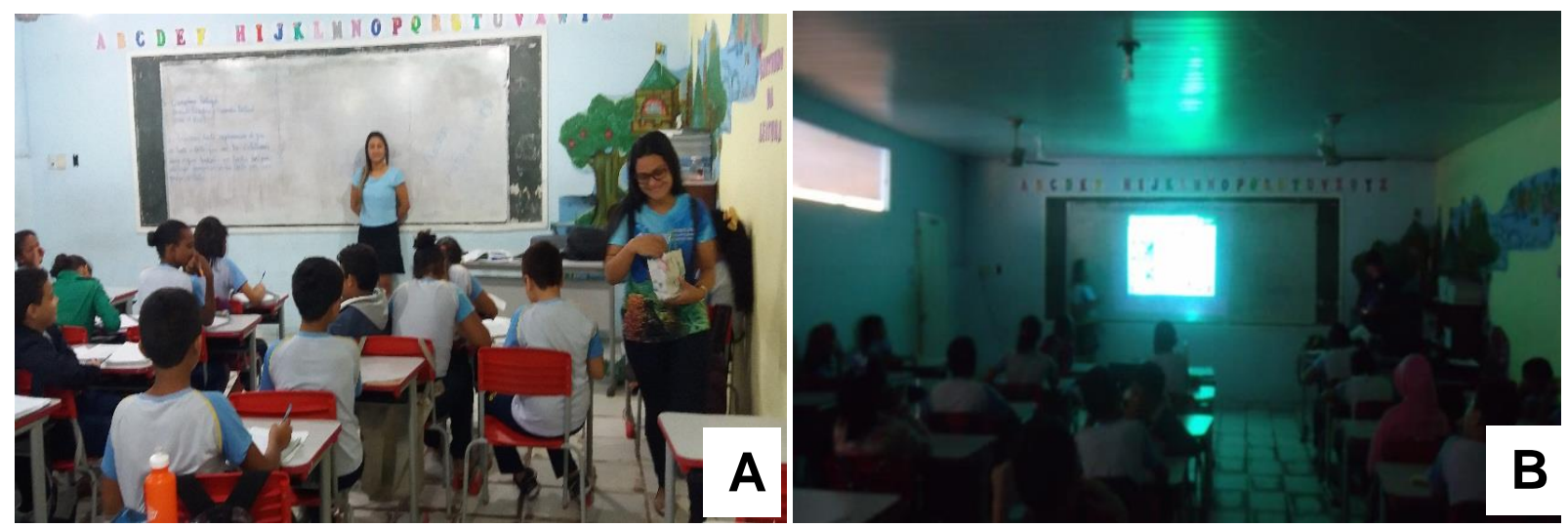

Figura 8: (A) palestra sobre pesca e aquicultura para os alunos e (B) atividade virtual de ensino/aprendizagem com os estudantes, Breves, Ilha do Marajó, Pará, Brasil. 
percepção dos estudantes e discutir recursos pesqueiros com foco no meio ambiente agregaram conhecimento para eles, mostrando a eficácia do projeto na escola (Figura 10). Percebemos a importância de trabalhar temas socioambientais atrelados a atividades econômicas do Marajó, a partir das técnicas de Educação Ambiental. Analisando a aceitação geral, pode-se verificar que os estudantes participaram das discussões ambientais a partir da perspectiva da pesca e aquicultura Outros trabalhos realizados nessa área já mostraram relevância nesse tipo de pesquisa, entre eles o de Reigota e Tozoni-Reis (2008) e Varotto e Araújo (2016) que, através de seus resultados, enfatizam que as técnicas de EA, a partir da piscicultura, é capaz de promover a responsabilidade e a sensibilização da sociedade.

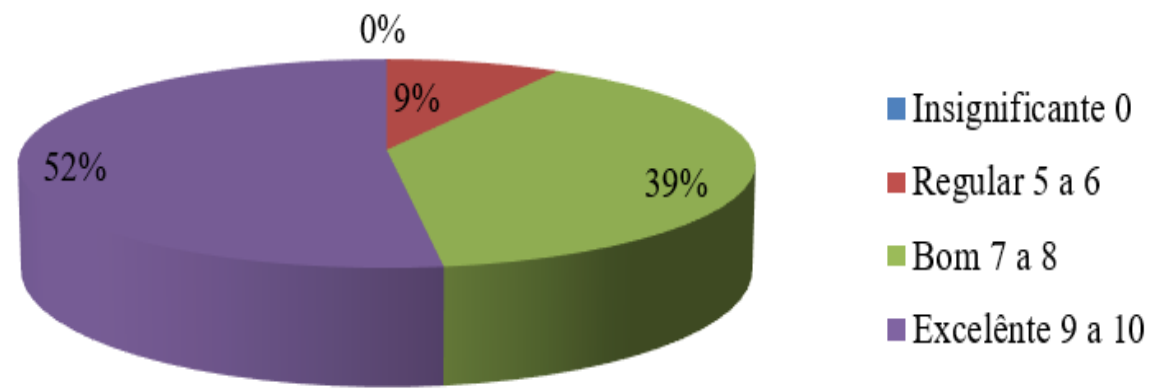

Figura 9: Projeto sobre pesca, aquicultura e meio ambiente contribuiu para ampliar os conhecimentos (técnica escala hedônica facial), Breves, llha do Marajó, Pará, Brasil.

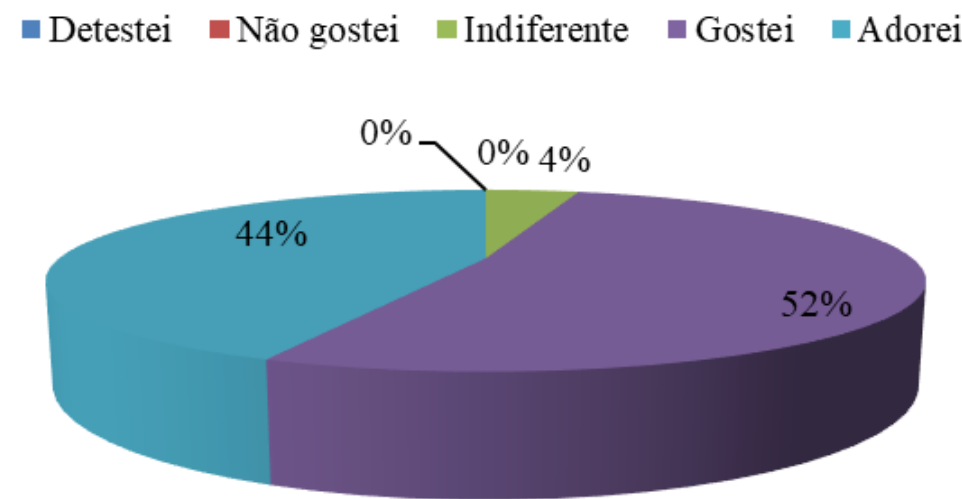

Figura 10: Criar peixe em viveiros escavados na percepção dos estudantes (técnica escala hedônica facial), Breves, Ilha do Marajó, Pará, Brasil.

\section{Considerações finais}

A abordagem da pesca e aquicultura, por meio das técnicas de Educação Ambiental (EA), foi importante na formação socioambiental e cidadã dos educandos do ensino fundamental. Porém, o papel da escola é abordar o tema EA, levando em consideração as especificidades socioeconômica e culturais locais, ainda é pouco difundido, para que ocorra sucesso no ensinoaprendizagem. 


\section{Agradecimentos}

Ao Instituto Federal de Educação, Ciência e Tecnologia do Pará (IFPA) Campus Breves, pela produção desse trabalho de conclusão do Curso Técnico Subsequente em Meio Ambiente. À Escola de Ensino Fundamental Adventista de Breves, pela contribuição na pesquisa realizada.

\section{Referências}

AFONSO, S.L.A. Diferenças no reconhecimento de expressões Faciais de emoção em ocupações laborais distintas. Dissertação de Mestrado (Programa de Pós-graduação em Ciências do Comportamento, do Departamento de Processos Psicológicos Básicos, Instituto de Psicologia). Universidade de Brasília, 65p, 2017.

ALARCON, A.M.Y.; BOELTER, R.A. O meio ambiente segundo alunos do 5은 ano do ensino fundamental. Revista Insignare, Scientia, v. 2, n. 2, 2019.

APPOLO, C.B.; NISHIJIMA, T. Educação Ambiental voltada à piscicultura praticada por pequenos produtores rurais. Revista Eletrônica em Gestão, Educação e Tecnologia Ambiental, v.2, n², p. 214 - 224, 2011.

BRASIL. Política Nacional de Educação Ambiental, Lei no 9.795. Diário Oficial da República Federativa do Brasil. Brasília, DF, 27 abr. 1999. Disponível em: <http://www.planalto.gov.br/ccivil 03/Leis/L9795htm>. Acesso em: 10 julho. 2019.

BRASIL. Conselho Nacional de Educação; Câmera de Educação Básica. Resolução no7, de $\mathbf{1 4}$ de dezembro. Fixa Diretrizes Curriculares Nacional para o Ensino Fundamental de (9) anos. Diário Oficial da União, Brasília, 15 de dezembro de 2010.2 Disponível em: http://portal.mec.gov.br/dmdocuments/rceb007 10.pdf>. Acesso em: 03 set. 2019.

BRASIL. Conselho Nacional de Educação; Câmera de Educação Básica. Resolução no7, de 14 de dezembro. Fixa Diretrizes Curriculares Nacional para o Ensino Fundamental de (9) anos. Diário Oficial da União, Brasília, 15 de dezembro de 2010.2 Disponível em: http://portal.mec.gov.br/dmdocuments/rceb007 10.pdf>. Acesso em: 03 set. 2019.

BRASIL. Secretaria de Educação Fundamental. Parâmetros Curriculares Nacionais: meio ambiente e saúde. Brasília: MEC/ SEF, 1997. Disponível em:< http://portal.mec.gov.br/seb/arquivos/pdf/livro091.pdf>. Acesso em: 03 set. 2019.

BRASIL. Secretaria de Educação Fundamental. Parâmetros Curriculares Nacionais: ciências naturais. Brasília: MEC/ SEF, 1998. Disponível em:< http://portal.mec.gov.br/seb/arquivos/pdf/ciencias.pdf>. Acesso em: 03 Set. 2019. 
BALDISSEROTTO, B.; BARATA, L.E.S.; SILVA, A.S.; LOBATO, W.F.F.; SILVA, L.L.; TONI, C.; SILVA, L.V.F. Anesthesia of tambaqui Colossoma macropomum (Characiformes: Serrasalmidae) with the essential oils of Aniba rosaeodora and Aniba parviflora and their major compound, linalool. Neotropical Ichthyology, 16(1), 170-128, 2018.

BERGANO, M.C.B; GARBIM, T. Ensino de natureza e sociedade na educação infantil. Londrina: editora e distribuidora S.A., 2017.

BONZANINI, T.K.; NUNES, A.B. O uso de vídeos em trabalhos com Educação Ambiental na Educação Básica, ambientalMENTEsustentable, v. II, n. 20, 1391-1409, 2015.

BOTELHO FILHO, G.F.; OLIVEIRA, N.A. A vida no aquário. São Paulo: Nobel, 1984.

BROWNSCOMBE, J. W.; HYDER, K.; POTTS, W.; WILSON, K.L.; POPE, K.L.; DANYLCHUK, A.J.; POST, J.R. The future of recreational fisheries: Advances in science, monitoring, management, and practice. Fisheries Research, 211, 247-255, 2019.

DAIRIKI, J.K.; SILVA, T.B.A. Revisão de literatura: exigências nutricionais do tambaqui- complicação de trabalho, formulação de ração adequadas e desafios futuros. Manaus: Embrapa Amazônia Ocidental, 2011.

DORIA, C.R.C.; LIMA, M.A.L.; ANGELINI, R. Ecosystem indicators of a smallscale fisheries with limited data in Madeira river (Brazil). Boletim do Instituto de Pesca, 44(3): 317, 2018.

DUTCOSKY, S.D. Análise sensorial de alimentos, 2ed. - Curitiba: Champagnat, 2007.

FERREIRA, L.C.; MARTINS, L.C.G.F.; PEREIRA, S.C.M.; RAGGI, D.G.; SILVA, J.G.F. Educação Ambiental e sustentabilidade na prática escolar. Revista Brasileira de Educação Ambiental, v. 14, n 2: 201-214, 2019.

FRIEDLANDER, A.M. Marine conservation in Oceania: Past, present, and future. Marine Pollution Bulletin, 135, 139-149, 2018.

GARUTTI, V. Piscicultura ecológica. São Paulo: Unesp, 332 p., 2003.

GIL, A.C. Metas e técnicas de Pesquisa Social. 6 ed. São Paulo: ATLAS. 2012.

GONÇALVES, A.F.; SILVEIRA, A.S.; CRISTO, J.P.; GATINHO, R.G.B.S.; PEREIRA JUNIOR, A. A Educação Ambiental e o ensino de ciências (6으 ao 9o ano) na escola pública e privada. Revista Brasileira de Educação Ambiental, v. 14, n. 1: 394-415, 2019.

IBGE - Instituto Brasileiro de Geografia e Estatística. Censo demográfico brasileiro. Rio de Janeiro, 2010. Disponível em. $<$ http://www.ibge.gov.br/home/>. 
KLOETZEL, K.O. O que é meio ambiente. 2. ed. São Paulo: Brasiliense, 1998. (coleção primeiros passos).

LÍSBOA, M.; BARROS, J. Direito Humano ao Meio Ambiente. [S. I.]: INSC, 2008. Disponível em: <http://www.turminha.mpf.mp.br/para-oprofessor/publicacoes/Direito\%20Humano\%20a0\%20Meio\%20Ambiente.pdf>.

Acesso em: 10 julho. 2019.

LLORET, J., COWX, I.G., CABRAL, H., CASTRO, M., FONT, T., GONÇALVES, J.M.S.; ERZINI, K. Small-scale coastal fisheries in European Seas are not what they were: Ecological, social and economic changes. Marine Policy, 98, 176186, 2016.

MACIEL, C.R.; VALENTI, W.C. Effect of tank colour on larval performance of the Amazon River prawn Macrobrachium amazonicum. Aquaculture Research, 45(6), 1041-1050, 2014.

MAGALHÃES, L.M.F. Plano De Educação Ambiental do Município de Breves; Princípios; Diretrizes e Políticas. Belém: Paka-Tatu, 2010.

MAGNUSSON, W.E. Turtle management as scientific experimentation. Chelonian Conservation and Biology, 4(3):722-723, 2003.

MEDEIROS, A.B.; MENDONÇA, M.J.S.L.; SOUSA, G.L.; OLIVEIRA, I.P. A Importância da Educação Ambiental na escola nas séries iniciais. Revista Faculdade Montes Belos, v. 4, n. 1, 2011.

MELO, S.S.; TRAJBER, R. Vamos cuidar do Brasil: conceitos e práticas em Educação Ambiental na escola. Brasília: Ministério da Educação, Coordenação Geral de Educação Ambiental: Ministério do Meio Ambiente, Departamento de Educação Ambiental: UNESCO, 2007.

MENEZES, T. A.; MENDONÇA, C. M. L. A.; ARAGÃO, U. S. A utilização de aquários e terrários como ferramenta de ensino: um olhar pelo viés da experimentação. In: Seminário de Iniciação Científica (SEMIC). Anais... Universidade Estadual de Feira de Santana/BA. UEFS, 2011.

NEVES, J.M.; COELHO, A.; PERALTA, N. Pescadores, barcos e frigoríficos: um estudo da cadeia produtiva do peixe liso na região de Tefé (AM). Revista GeoAmazônia, v. 07, n. 13, p. 183-201, 2019.

OLIVEIRA, C.C.; CHAGAS, R.J.; TEIXEIRA, P.M.M. A utilização de aquário como recurso didático para o ensino de Ciências em uma escola pública de Jequié/BA. Anais... Atas do IX Encontro Nacional de Pesquisa em Educação em Ciências - IX ENPEC Águas de Lindóia, SP - 10 a 14 de Novembro de 2013.

OLIVEIRA, C.C.; JUCÁ-CHAGAS, R.; TEIXEIRA, P.M.M. O uso do aquário no ensino de Ciências em uma escola pública do município de Jequié/BA. In: XI Congresso Nacional de Ecologia e I Congresso Internacional de Ecologia. Anais... Porto Seguro: SBE, 2013. 
REIGADA, C.; TOZONI-REIS, M. Educação Ambiental para crianças no ambiente urbano: uma proposta de pesquisa-ação. Ciência \& Educação, v. 10, n. 2, p. 149-159, 2004.

REIGOTA, M. Meio ambiente e representação social. 7. ed. São Paulo: Cortez. 2007.

SAMPAIO, D.S.; TAGLIARO, C.H.; SCHNEIDER, H.; BEASLEY, C.R. Oyster culture on the Amazon mangrove coast: asymmetries and advances in an emerging sector. Reviews in Aquaculture, 0, 1-17, 2017.

SILVA JÚNIOR, A.R.; RODRIGUES, S.C.M.; CARVALHO, A.C. Pesca predatória do mapará (Hypophthalmus spp.) no município de Limoeiro do Ajuru (PA) e Educação Ambiental como instrumento mediador de interesses e conflitos. Revista Brasileira de Educação Ambiental, v. 14, n 1: 81-100, 2019.

SILVA, F.N.L.; OLIVEIRA, L.C.; MANGAS, T.P.; SANTOS, A.S.; SILVA, F.R.; SANTOS, R.A. Cenário atual da atividade aquícola familiar em comunidades no município de Breves, ilha do Marajó, Pará, Brasil. Revista Unimar Ciências, v. 26, p. 1-2, 2017.

SOUZA, A.M.; MURATA, A.T. A piscicultura como estratégia de ensino nas escolas de educação do campo. Universidade Federal do Paraná, 14p, 2013.

TERTULIANO, S.A.; FIORI, S. Educação Ambiental nos anos iniciais do ensino fundamental: construindo sabers. Arquivos do MUDI, v 23, n 2, p. 111-128, 2019.

TOZONI-REIS, M.F.C. Metodologias Aplicadas à Educação Ambiental, 2 ed. Curitiba: IESDE Brasil, S. A., 2008.

VAROTTO, D.; ARAÚJO, L. Piscicultura e desenvolvimento sustentável: a piscicultura como estratégia de ensino no centro estadual de educação profissional agrícola Fernando Costa. Paraná, Cadernos PDE, v.1, 2016.

VERDELONE, T.H.; CAMPBELL, G.; ALEXANDRINO, C. Trabalhando Educação Ambiental com turmas do ensino fundamental I. Brazilian Journal of Development, Curitiba, v. 5, n. 6, p. 4675-4687, 2019.

VIANA, E.C.S.; OLIVEIRA JÚNIOR, G.M.; SOBRAL, E.C.M.N.C.; SOBRAL, S.E.C.; LIMA, O.M.L. A Educação Ambiental nos anos Iniciais do Ensino Fundamental. Revista Multidisciplinar e Psicologia, v. 13, n. 44, p. 620-634, 2019. 